\title{
UTILIZAÇÃO DE UMA ÁREA DE PROTEÇÃO AMBIENTAL POR UMA COMUNIDADE DE ELASMOBRÂNQUIOS NO ATLÂNTICO SUL OCIDENTAL
}

\author{
Georgia Maria de Oliveira Aragão ${ }^{1 *}$, Jorge Eduardo Kotas², Henry Louis Spach $^{3}$ \\ ${ }^{1}$ Discente no Programa de Pós-Graduação em Sistemas Costeiros e Oceânicos, Universidade Federal do Paraná, \\ bolsista Capes, End. Pontal do Paraná - PR, 83255-000, Universidade Federal do Paraná, Centro de Estudos do Mar. \\ E-mail: georgia.aragao@gmail.com \\ ${ }^{2}$ Analista Ambiental, ICMBIO-CEPSUL, End. Av. Carlos Ely Castro, 195 - Centro, Itajaí - SC, 88301-445. E-mail: \\ jorge.kotas@icmbio.gov.br \\ ${ }^{3}$ Docente, Programa de Pós-Graduação em Sistemas Costeiros e Oceânicos, Universidade Federal do Paraná, bolsista \\ Capes, End. Pontal do Paraná - PR, 83255-000, Universidade Federal do Paraná, Centro de Estudos do Mar. E-mail: \\ henry@ufpr.br
}

\begin{abstract}
RESUMO
Globalmente a explotação dos peixes cartilaginosos marinhos é cada vez mais crescente principalmente em áreas costeiras. Entretanto, existem áreas no Atlântico Sul Ocidental que ainda são pouco conhecidas quanto a sua biodiversidade de elasmobrânquios. Portanto, o objetivo deste trabalho é de conhecer a comunidade de elasmobrânquios marinho-estuarinos e suas respectivas áreas de uso em uma unidade de conservação de uso sustentável (APA do Delta do Parnaíba), no nordeste do Brasil, a partir do monitoramento dos desembarques da pesca artesanal na região. A partir do monitoramento de 1184 desembarques realizados entre janeiro de 2016 e janeiro de 2017, foi possível identificar nove espécies de tubarões (Carcharhinus leucas, C. porosus, C. acronotus, C. limbatus, Galeocerdo cuvier, Sphyrna mokarran, S. lewini, Rhizoprionodon porosus e Ginglymostoma cirratum) e sete espécies de raias (Hypanus guttatus, H. americanus, H. marianae, Fontitrygon geijskesi, Gymnura micrura, Aetobatus narinari e Rhinoptera bonasus) que fazem uso de três áreas batimetricamente distintas. As espécies com as maiores frequências de ocorrência foram R. porosus (36\%) e H. gutattus (61\%). Os resultados demonstram que a área é utilizada por distintas espécies, dentre elas espécies consideradas em risco de extinção, como o S. mokarran. Palavras-chave: seláceos, batoideos, biologia da conservação.
\end{abstract}

\section{ABSTRACT}

\section{USE OF AN ENVIRONMENTAL PROTECTION AREA BY A COMMUNITY OF ELASMOBRANCHS IN THE TROPICAL SOUTHWESTERN ATLANTIC}

Worldwide the exploitation of marine cartilaginous fish is increasing, mainly in coastal regions. However, there are areas in the Southwestern Atlantic that are still little known about their elasmobranch biodiversity. Therefore, this work aims to know the community of marine estuarine elasmobranchs and their respective areas of use in a sustainable use conservation unit (APA of the Parnaíba Delta), in the northeast of Brazil, from the monitoring of the landings of the fishing in the region. From the monitoring of 1184 landings between January 2016 and January 2017, it was possible to identify nine species of sharks (Carcharhinus leucas, C. porosus, C. acronotus, C. limbatus, Galeocerdo cuvier, Sphyrna mokarran, S. lewini, Rhizoprionodon porosus and Ginglymostoma cirratum) and seven species of stingrays (Hypanus guttatus, H. americanus, $H$. marianae, Fontitrygon geijskesi, Gymnura micrura, Aetobatus narinari and Rhinoptera bonasus) which make use of three different depth ranges. The most frequent species were $R$. porosus $(36 \%)$ and $H$. gutattus (61\%). The results demonstrate that the area is used by different species, among them species considered endangered, such as S. mokarran.

Key words: selachians, batoids, conservation biology. 


\section{INTRODUÇÃO}

Atualmente a maior ameaça aos elasmobrânquios (tubarões e raias) é a ação antrópica, seja pela pesca excessiva ou pela degradação dos ambientes costeiros. A degradação ambiental agrava a situação dos estoques sobre-explotados e pode levar algumas espécies ao risco de extinção (Steven et al. 2000; Simpfendorfer et al. 2002; Dudley and Simpfendorfer 2006; Dulvy et al. 2014; Ferretti et al. 2010). A gestão da pesca dos peixes cartilaginosos, um grupo com estratégias de vida e características únicas, certamente requer medidas específicas e mais rigorosas do que as que costumam ser adotadas para outros organismos aquáticos (Dias Neto, 2011), visto que cerca de $25 \%$ das espécies descritas sofrem algum nível de ameaça (Dulvy et al., 2008). Os elasmobrânquios se apresentam como um dos grupos taxonômicos mais impactados, com altas taxas de declínio em períodos curtos de tempo, em especial os tubarões (Ferretti et al., 2008).

Apesar de constituírem um grupo particularmente susceptível à sobrepesca, com populações que diminuíram em até $90 \%$ em algumas regiões (Dent \& Clarke, 2015; Fonteles-Filho, 2011), considerável parte das capturas não é identificada ao nível de espécie, sendo apenas agrupadas em categorias genéricas como "tubarões" e "raias", impossibilitando estudos que avaliem o estado de conservação das diferentes espécies.

Os elasmobrânquios ocupam níveis elevados da cadeia trófica e participam de maneira marcante no intercâmbio de energia do ambiente em que vivem, utilizando desde regiões estuarinas a altas profundidades. Apesar da atual distribuição global da maioria das espécies, Cheung et al. (2009) e Dulvy et al. (2008) apontam que alterações climáticas podem afetar de forma significativa os padrões de distribuição e posição trófica, adicionando um desafio extra para a conservação do grupo.

O Brasil apresenta uma biodiversidade considerável de condrícteos. Existem pelo menos 169 espécies descritas, ou seja, 89 tubarões, 70 raias e seis quimeras, distribuidos em sua maioria em ambientes marinhos e estuarinos (Rosa e Gadig, 2014). Segundo Dent \& Clarke (2015) o Brasil captura em média 20992 t/ano de tubarões. As estatísticas oficiais de pesca não diferenciam as quantidades desembarcadas por espécie, sendo agregadas em categorias como "cações" e "raias". $\mathrm{Na}$ maioria dos casos são apenas registradas as carcaças desembarcadas e portanto, as verdadeiras quantidades capturadas são desconhecidas (Vooren et al. 2005). Os dados disponíveis mostram que a produção nacional de tubarões atingiu um pico de 23717 t em 1982, declinando a patamares médios de 11137 t entre 2008 e 2010, não havendo sinais de recuperação. Para as raias, a produção atingiu um pico de 8153 t em 2005 e um mínimo de 5279 t em 2007, porém sem sinais de declínio (Dias-Neto, 2015).

Declínios acentuados nas populações locais de elasmobrânquios costeiros já foram detectados nas regiões norte e nordeste do Brasil, como é o caso do cação-quati Isogomphodon oxyrhynchus, espécie endêmica que declinou mais de $90 \%$ nos últimos 40 anos, estando em estágio de quase-extinção (Lessa, 1986; Stride et al. 1992; Lessa, 1997; Lessa et al. 1999; Lessa et al. 2000; Santana \& Lessa, 2002; Rodrigues-Filho et al. 2009; M. Almeida, com. pess., 2010; Lessa et al. 2016; Feitosa et al. 2018) e dos peixes-serra Pristis pectinata e Pristis pristis que já são considerados extintos no sudeste e sul do Brasil e restritos apenas aos litorais do Amapá, Pará, Maranhão e rio Amazonas (Charvet-Almeida, 1999; Menni \& Stehmann, 2000; Amorim et al. 2002; Burgess et al. 2009; Faria \& Charvet-Almeida, 2008). A pesca costeira incidental e dirigida, bem como a degradação dos habitats (manguezais) foram os responsáveis por esse cenário de diminuição dessas populações e as capturas continuam (Rodrigues-Filho et al. 2012; Palmeira et al. 2013; Dulvy et al., 2014; Ferreira \& Lacerda, 2016; Feitosa et al. 2018).

A APA do Delta do Parnaíba é uma área de proteção ambiental, criada por meio de decreto pelo governo federal em 28 de agosto de 1996 (http://www. planalto.gov.br/ccivil_03/DNN/Anterior $\% 20 \mathrm{a} \% 20$ 2000/1996/Dnn4368.htm), abrangendo municípios costeiros do Maranhão (Paulinho Neves, Água Doce do Maranhão, Araioses e Tutóia), Piauí (Ilha Grande, Luís Corrêa, Cajueiro da Praia e Parnaíba), e Ceará (Chaval e Barroquinha). Em sua jurisdição ocorrem ambientes dos mais variados como os rios Parnaíba, Timonha e Ubatuba e seus respectivos deltas, complexos dunares, remanescentes de mata aluvial, caatinga litorânea, carnaubais, restingas, praias arenosas e manguezais. Nesse ambiente heterogêneo, populações tradicionais ali residem, vivendo da pesca, agricultura, artesanato e do ecoturismo. Os recursos marinho-costeiros são explorados por meio da pesca e coleta manual, como é o caso do caranguejo uçá, ostras e mariscos (IBAMA, 1998). Segundo o censo do IBGE de 2018 um total de 360.671 habitantes residiam nessa APA. Na APA do Delta do Parnaíba a pesca é predominantemente artesanal, sendo a linha de mão o apetrecho mais 
utilizado com frequência de $42 \%$. Nesse mesmo contexto, os elasmobrânquios compõem 7,4\% do volume de pesca na região (IBAMA, 2011). A área é considerada de grande importância para a conservação ambiental, pois além de ser uma APA, é uma área de transição entre a região norte e nordeste do Brasil sofrendo influências da Zona de Convergência Intertropical (Medeiros, 1996).

Nesse contexto, o objetivo deste estudo foi conhecer a comunidade de elasmobrânquios marinho-estuarinos da APA do Delta do Parnaíba, ou seja, identificar as diferentes espécies e suas diferentes áreas de uso, com base no monitoramento dos desembarques da pesca de pequena escala.

\section{MATERIAL E MÉTODOS}

\section{Área de estudo}

A Área de Preservação Ambiental (APA) do Delta do Parnaíba apresenta uma área total de $304.295,74$ ha, sendo que $183.841,45$ ha estão no estado do Maranhão (60,5\%), 97.630,82 ha no estado do Piauí $(32 \%)$ e $22.823,47$ ha no estado do Ceará (7,5\%) (Figura 1).

A temperatura atmosférica média anual varia entre $25^{\circ}$ e $27^{\circ} \mathrm{C}$, com precipitações que superam os $1200 \mathrm{~mm}$ e se concentram principalmente entre os meses de janeiro a maio $(80 \%)$ e de agosto a novembro são registrados os menores índices pluviométricos. O clima predominante é $A w /$ Equatorial com inverno seco (Stride, 1992; Kottek et al. 2006).

Ao longo da costa a Corrente Costeira Norte Brasileira (CCNB), impulsionada pelos ventos alísios de sudeste, transporta as águas da plataforma continental externa e do talude na direção noroeste, com uma velocidade de até $1,2 \mathrm{~m} / \mathrm{s}$ (Richardson et al. 1994; Fonseca et al. 2000). No litoral a temperatura da superfície do mar varia entre 26 a $29^{\circ} \mathrm{C}$. A salinidade apresenta médias de 33,8\%o em águas costeiras e 36,8 \%o em águas oceânicas (CHM, 2014; DHN, 2014). A massa d'água presente plataforma continental é a água Tropical, caracterizada por temperaturas e salinidades altas (Pontes \& El-Robrini, 2008). Em termos de amplitudes de marés em Tutóia atingem 3 a 4 m (Palma, 1979). Nas proximidades do Rio Parnaíba a largura da plataforma continental é de aproximadamente $100 \mathrm{~km}$ (Gonçalves et al. 2003).

\section{Coleta e análise dos dados}

Os monitoramentos dos desembarques foram realizados quinzenalmente no ponto 3 da figura 1 (pesqueira da Pedra do Sal), no período de janeiro de 2016 a janeiro de 2017. A duração da coleta no campo foi de cinco dias consecutivos. Durante o monitoramento foram efetuadas, por meio de formulários, 1.184 entrevistas com os pescadores para o levantamento das informações sobre as capturas em número de indivíduos por espécie, por modalidade pesqueira (redes-de-emalhe e linhasde-mão) e seus locais de ocorrência (anexo 1). Os pontos de pesca foram distribuídos espacialmente, utilizando-se o critério batimétrico de Cuevas et.al., (2013). Desta forma, foram estabelecidos três estratos batimétricos: I (21 a 30m), II (11 a $20 \mathrm{~m})$ e III (0 a $10 \mathrm{~m}$ de profundidade).

Para o estudo da estrutura da comunidade de elasmobrânquios na APA do Parnaíba a similaridade entre as espécies foi avaliada através do índice de Bray-Curtis. Foram utilizadas duas técnicas de análise, ou seja: a) Análise de agrupamento (Cluster)

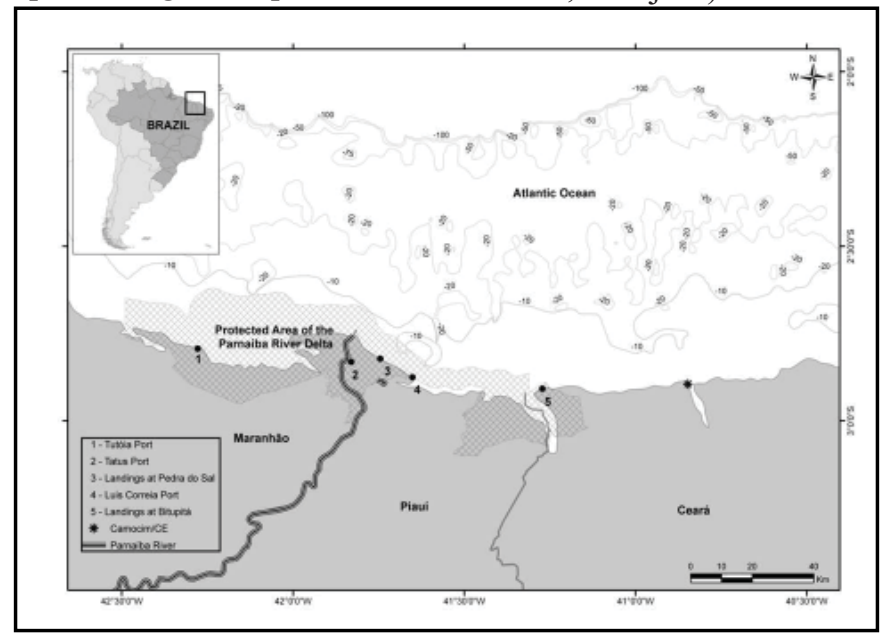

Figura 1. APA do Delta do Parnaíba, Brasil, com os principais pontos de desembarques da pesca artesanal $(1-5)$. 
com teste de perfil de semelhança (SIMPROF) com 1000 simulações, verificando a significância $(\mathrm{p}<$ 0,05 ) dos agrupamentos formados no cluster (Clarke \& Gorley, 2006); b) Análise de ordenação (NMDS Non-Metric Multidimensional Scaling) considerando valores do coeficiente de estresse menores do que 0,05 uma excelente representação (Kruskal, 1964; Clarke \& Warwick, 1994). Também foram elaborados diagramas de Shepard (1962) para verificar a validez do MDS (Clarke \& Warwick, 1994). Para avaliar se existiam diferenças significativas na diversidade de Shannon-Wiener (H'(log e)) e na ocorrência de raias e tubarões entre os estratos batimétricos e entre as estações chuvosa e seca, foi aplicada a análise de variância multivariada por meio de permutações (PERMANOVA - Permutational multivariate analysis of variance) (Anderson et al., 2008). A análise de similaridade de percentagem (SIMPER) foi utilizada para identificar quais espécies de raias e tubarões foram mais responsáveis pela similaridades e dissimilaridades entre as áreas de pesca e estações chuvosa e seca (Clarke \& Gorley, 2006).

\section{RESULTADOS}

Diversidade de espécies e estado de conservação

Foram identificadas nove espécies de tubarões e sete de raias. Dentre os tubarões $(\mathrm{n}=77), R$. porosus (36\%), S. mokarran (20\%) e G. cirratum (16\%), apresentaram frequência maior que $10 \%$ no período considerado, enquanto $C$. porosus apresentou a menor ocorrência (1\%). Dentre as raias $(\mathrm{n}=207), H$. guttatus (61\%) e H. americanus (14\%) apresentaram valores maiores que $10 \%$, enquanto $H$. marianae foi a de menor incidência nas capturas $(0,9 \%)$ (Figura 2).

Em relação ao estado de conservação das espécies capturadas na região considerando a avaliação do ICMBio /MMA (2018), 04 são listadas como ameaçadas de extinção (S. mokarran - Em Perigo (EN); S.lewini - Criticamente em Perigo (CR) , G. cirratum - Vulnerável (VU) e C. porosus - Criticamente em Perigo (CR)) e 06 espécies com dados insuficientes (DD), sendo desconhecido seu estado de conservação devido à falta de dados como distribuição e níveis de abundância relativa $(R$. porosus, $H$. americanus, $H$. marianae, $R$. bonasus, A. narinari e F. geijskesi) (Tabela 1).

A distribuição batimétrica foi inicialmente avaliada para os elasmobrânquios separados em dois grupos, ou seja, tubarões e raias (Figura 3a). Neste caso, se observa que ambos os grupos estiveram mais concentrados entre as profundidades de 11 a $20 \mathrm{~m}$.

Ao considerar as espécies de tubarões individualmente, R.porosus e G.cirratum estiveram concentradas entre 11 e $20 \mathrm{~m}$ de profundidade. Por sua vez S. mokarran e C.acronotus ocorreram com mais freqüência no estrato de 20 a $30 \mathrm{~m}$ (Figura 3 b). Já C.limbatus esteve concentrado em menores profundidades, entre 0 e $20 \mathrm{~m}$.

No caso das raias, H.guttatus, H.americanus e R.bonasus, estas se concentraram no extrato de 11 a $20 \mathrm{~m}$ (Figura $3 \mathrm{c}$ ).

Ao considerar as estações chuvosa e seca, os grupos dos tubarões e das raias foram mais freqüentes na estação chuvosa (Figura 4 a).

Considerando as diversas espécies de tubarões em separado (Figura 4 b), S.mokarran, R.porosus, G.cirratum e C.acronotus foram mais freqüentes na estação seca. No caso das raias, H.guttatus apresentou maior incidência no período chuvoso (Figura 4 c). Por sua vez, H.americanus, R.bonasus e G.micrura ocorreram com maior freqüência na estação seca.

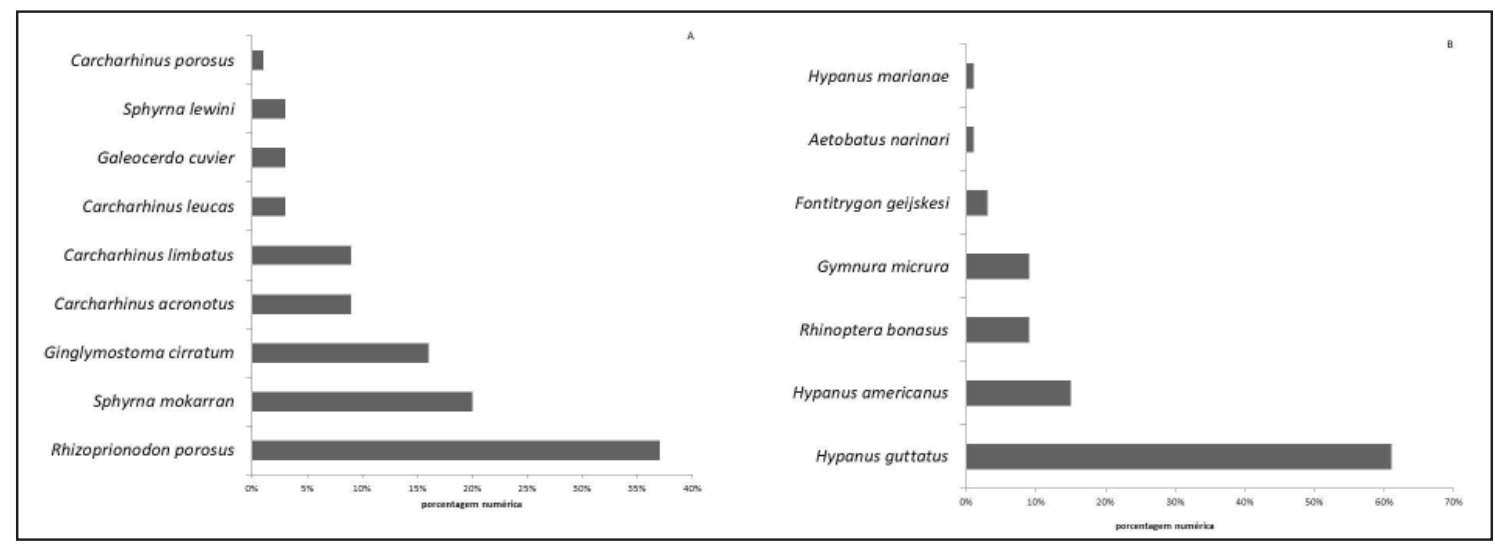

Figura 2. Percentual numérico das espécies de tubarões (A) e raias (B) que ocorreram nas capturas da pesca artesanal na APA do delta do Parnaíba. 
Tabela 1. Elasmobrânquios desembarcados pela frota artesanal no ponto 3 (Pedra do Sal- PI) e seus respectivos estados de conservação, segundo avaliação nacional/ICMBio (2016) e global (IUCN red list). Os números são as frequências de ocorrência $(\mathrm{N})$ das diferentes espécies por extrato batimétrico e estação (chuvosa/seca). CR- Criticamente em Perigo, EM- Em perigo, VUVulnerável, NT- Próximo da ameaça, LC- Pouco Preocupante, DD-Deficiente de Dados.

\begin{tabular}{|c|c|c|c|c|c|c|c|}
\hline Nome científico & Nome popular & $\begin{array}{c}\text { Avaliação } \\
\text { nacional }\end{array}$ & $\begin{array}{c}\text { Avaliação } \\
\text { global }\end{array}$ & $\begin{array}{c}\text { Extrato } \\
\text { batimétrico }\end{array}$ & $\mathbf{N}$ & Seca & Chuva \\
\hline \multirow{3}{*}{ Sphyrna mokarran } & \multirow{3}{*}{ Panã } & \multirow{3}{*}{$\mathrm{CR}$} & \multirow{3}{*}{ EM } & I & 7 & 5 & 2 \\
\hline & & & & II & 5 & 3 & 2 \\
\hline & & & & III & 4 & 1 & 3 \\
\hline \multirow{3}{*}{ Sphyrna lewini } & \multirow{3}{*}{ Panã safroa } & \multirow{3}{*}{$\mathrm{CR}$} & \multirow{3}{*}{ EM } & $\mathrm{I}$ & 2 & 1 & 1 \\
\hline & & & & II & & & \\
\hline & & & & III & & & \\
\hline \multirow{3}{*}{ Rhizoprionodon porosus } & \multirow{3}{*}{ Rabo seco } & \multirow{3}{*}{ DD } & \multirow{3}{*}{$\mathrm{LC}$} & $\mathrm{I}$ & 6 & 3 & 3 \\
\hline & & & & II & 17 & 9 & 8 \\
\hline & & & & III & 6 & 4 & 2 \\
\hline \multirow{3}{*}{ Ginglymostoma cirratum } & \multirow{3}{*}{ Cação Lixa } & \multirow{3}{*}{ VU } & \multirow{3}{*}{ DD } & $\mathrm{I}$ & 2 & 2 & \\
\hline & & & & II & 7 & 6 & 1 \\
\hline & & & & III & 4 & & 4 \\
\hline \multirow{3}{*}{ Galeocerdo cuvier } & \multirow{3}{*}{ Tigre } & \multirow{3}{*}{ NT } & \multirow{3}{*}{ NT } & $\mathrm{I}$ & 1 & 1 & \\
\hline & & & & II & 1 & & 1 \\
\hline & & & & III & & & \\
\hline \multirow{3}{*}{ Carcharhinus leucas } & \multirow{3}{*}{$\begin{array}{l}\text { Boca redonda ou } \\
\text { cabeça chata }\end{array}$} & \multirow{3}{*}{ NT } & \multirow{3}{*}{ NT } & $\mathrm{I}$ & & & \\
\hline & & & & II & 1 & & 1 \\
\hline & & & & III & 1 & & 1 \\
\hline \multirow{3}{*}{ Carcharhinus porosus } & & & & $\mathrm{I}$ & 1 & & 1 \\
\hline & Cação juntão & $\mathrm{CR}$ & $\mathrm{DD}$ & II & & & \\
\hline & & & & III & & & \\
\hline & & & & $\mathrm{I}$ & 3 & 3 & \\
\hline Carcharhinus acronotus & Cação flamengo & NT & NT & II & 2 & 2 & \\
\hline & & & & III & 2 & 1 & 1 \\
\hline & & & & $\mathrm{I}$ & 1 & & 1 \\
\hline Carcharhinus limbatus & Sacurí & NT & NT & II & 3 & & 3 \\
\hline & & & & III & 3 & 1 & 2 \\
\hline & & & & $\mathrm{I}$ & 32 & 19 & 32 \\
\hline Hypanus guttatus & $\begin{array}{c}\text { Raia bicuda ou } \\
\text { lixa }\end{array}$ & $\mathrm{LC}$ & DD & II & 72 & 50 & 22 \\
\hline & & & & III & 21 & 9 & 12 \\
\hline Hypanus americanus & & & & $\mathrm{I}$ & 6 & 5 & 1 \\
\hline & Raia de pedra* & DD & DD & II & 20 & 13 & 7 \\
\hline & & & & III & 4 & 4 & \\
\hline & & & & $\mathrm{I}$ & & & \\
\hline Hypanus marianae & Raia de pedra* & DD & DD & II & & & \\
\hline & & & & III & 2 & & 2 \\
\hline & & & & $\mathrm{I}$ & & & \\
\hline Fontitrygon geijskesi & Raia quati & DD & NT & II & 4 & 2 & 2 \\
\hline & & & & III & 2 & 2 & \\
\hline
\end{tabular}




\begin{tabular}{|c|c|c|c|c|c|c|c|}
\hline Nome científico & Nome popular & $\begin{array}{c}\text { Avaliação } \\
\text { nacional }\end{array}$ & $\begin{array}{c}\text { Avaliação } \\
\text { global }\end{array}$ & $\begin{array}{c}\text { Extrato } \\
\text { batimétrico }\end{array}$ & $\mathbf{N}$ & Seca & Chuva \\
\hline \multirow{3}{*}{ Rhinoptera bonasus } & \multirow{3}{*}{ Raia papagaio } & \multirow{3}{*}{$\mathrm{DD}$} & \multirow{3}{*}{ NT } & I & 5 & 2 & 3 \\
\hline & & & & $\mathrm{II}$ & 9 & 8 & 1 \\
\hline & & & & III & 5 & 5 & \\
\hline \multirow{3}{*}{ Gymnura micrura } & \multirow{3}{*}{$\begin{array}{l}\text { Raia borboleta ou } \\
\text { de fogo }\end{array}$} & \multirow{3}{*}{ NT } & \multirow{3}{*}{$\mathrm{DD}$} & $\mathrm{I}$ & & & \\
\hline & & & & II & 8 & 8 & \\
\hline & & & & III & 11 & 6 & 5 \\
\hline \multirow{3}{*}{ Aetobatus narinari } & \multirow{3}{*}{ Narim } & \multirow{3}{*}{$\mathrm{DD}$} & \multirow{3}{*}{ NT } & $\mathrm{I}$ & 1 & & 1 \\
\hline & & & & II & 1 & & 1 \\
\hline & & & & III & 1 & & 1 \\
\hline
\end{tabular}

* Raia de pedra é o nome popular de várias espécies de raias segundo os pescadores da APA do Delta do Parnaíba.

A PERMANOVA não detectou diferenças significativas $(\mathrm{p}<0,05)$ nas médias do número de indivíduos entre as estações e estratos batimétricos para tubarões e raias (Tabela 2 e 3 ).

A análise de similaridade de percentagens (SIMPER) entre as estações e os extratos batimétricos mostrou para os tubarões uma dissimilaridade média de $68 \%$ entre os períodos de seca e chuvoso, com maior contribuição significativa para esta dissimilaridade a maior presença de $R$. porosus, $S$. mokarran e G. cirratum no período seco e maior presença de C. limbatus no período chuvoso (Tabela 4 e Figura 4B). A maior presença de $R$. porosus e $G$. cirratum no extrato II, respondeu pela dissimilaridade média $(67 \%)$ em relação ao extrato I, onde houve maior participação de S.mokarran e C.acronotus (Tabela 4 e Figura 3B). A dissimilaridade média (74\%) entre os extratos I e III se deve principalmente a maior ocorrência de S. mokarran e C.acronotus no extrato I e de G. cirratum e C. limbatus no extrato III (Tabela 4 e Figura 3B). Finalmente, a dissimilaridade média (64\% ) entre os extratos II e III, foi devido a maior ocorrência de $R$. porosus, S. mokarran, $G$. cirratum no extrato II (Tabela 4 e Figura 3B).

Para as raias, o SIMPER indicou uma dissimilaridade média de $53 \%$ no padrão de

Tabela 2. Resultados do teste PERMANOVA das médias do número de tubarões (transformados pela raiz quarta). G1 = graus de liberdade e $\mathrm{MS}=$ soma dos quadrados médios.

\begin{tabular}{ccccc}
\hline $\begin{array}{c}\text { Fonte de } \\
\text { variação }\end{array}$ & Gl & MS & Pseudo-F & p (perm) \\
\hline $\begin{array}{c}\text { Extrato } \\
\text { batimétrico (E) } \\
\text { Estação (P) }\end{array}$ & 2 & 960,43 & 0,3374 & 0,926 \\
\hline E x P & 2 & 2093,6 & 0,7354 & 0,62 \\
\hline Resíduo & 25 & 2846,7 & & \\
\hline
\end{tabular}

ocorrência entre as estações seca e chuvosa, com a contribuição mais significativa das espécies $H$. americanus, $R$. bonasus e G. micrura, em ordem decrescente no período seco e H.guttatus no período chuvoso (Tabela 4, Figura 4C). Entre os extratos I e II, a dissimilaridade média foi de $55 \%$, sendo responsáveis principalmente as maiores ocorrências no extrato II das espécies $H$. guttatus, $H$. americanus, $R$. bonasus e G.micrura (Tabela 4, Figura 3C). A dissimilaridade média entre os extratos I e III foi de $72 \%$, devido principalmente a maiores ocorrências de G. micrura e R. bonasus na área III e de $H$. guttatus, $H$. americanus na área I (Tabela 4, Figura 3C). Finalmente as dissimilaridades entre os extratos II e III (64\%) foram devido às maiores ocorrências e H. guttatus, $H$. americanus, $R$. bonasus no extrato II e de $G$. micrura no extrato III (Tabela 4, Figura 3C).

O teste SIMPROF $(p<0,05)$ indicou a significância de dois agrupamentos na análise de Cluster das raias. O primeiro era formado por dois subgrupos ao nível de similaridade de $40 \%$, ou seja, um com H. americanus, $H$. guttatus e G. micrura, e o outro subgrupo com F. geijkesi e $R$. bonasus. Chama a atenção a similaridade entre $H$. americanus e $H$. guttatus e que foi a maior encontrada para as raias,

Tabela 3. Resultados do teste PERMANOVA das médias do número de raias (transformados pela raiz quarta). $\mathrm{Gl}=$ graus de liberdade e $\mathrm{MS}=$ soma dos quadrados médios.

\begin{tabular}{ccccc}
\hline $\begin{array}{c}\text { Fonte de } \\
\text { variação }\end{array}$ & Gl & MS & Pseudo-F & p (perm) \\
\hline $\begin{array}{c}\text { Extrato } \\
\text { batimétrico (E) } \\
\text { Estação (P) }\end{array}$ & 2 & 2278,7 & 1,0474 & 0,395 \\
\hline E x P & 2 & 1143,9 & 0,5258 & 0,723 \\
\hline Resíduo & 25 & 2175,6 & & 0,7499 \\
\hline
\end{tabular}




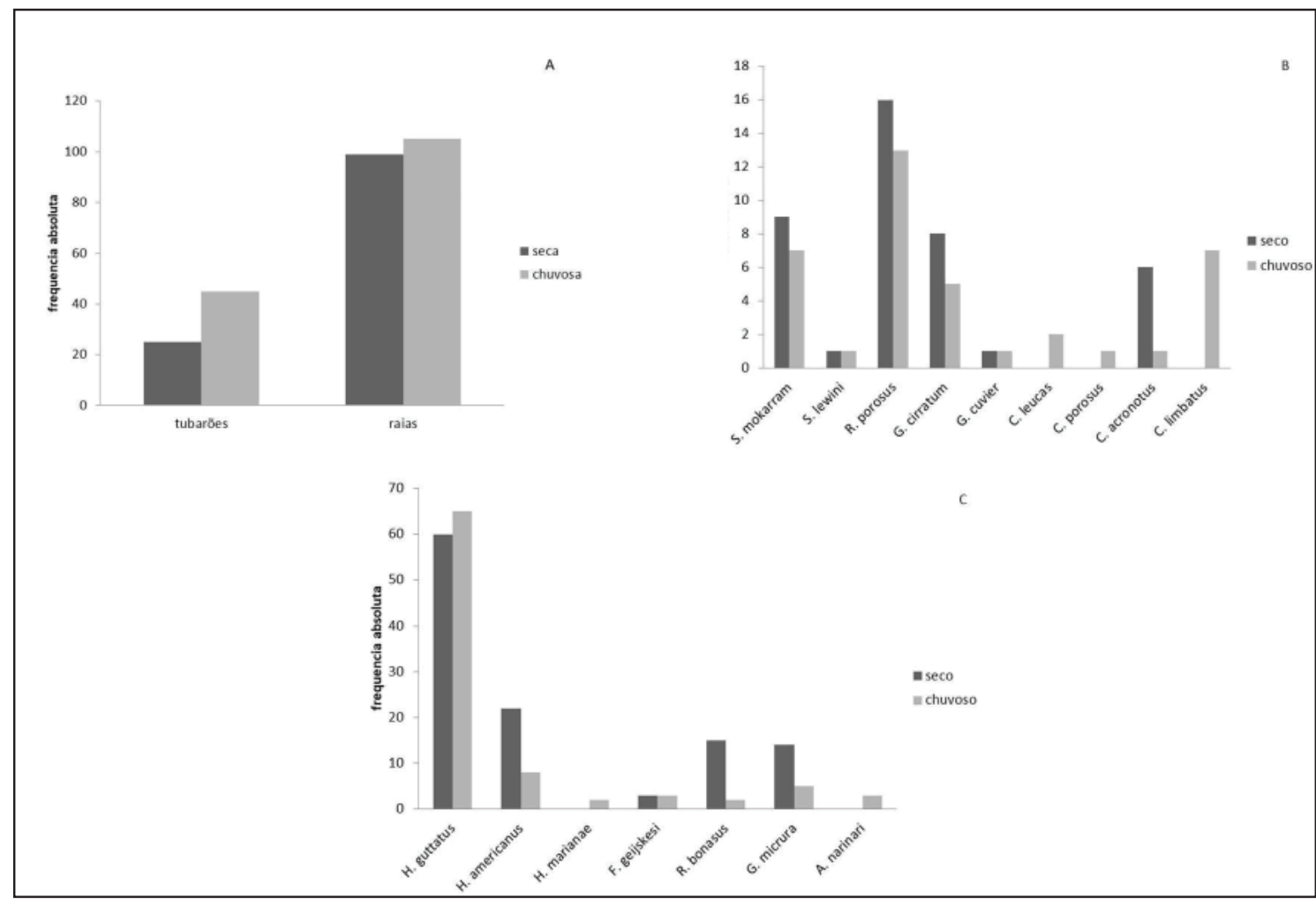

Figura 3. Distribuições de frequência absoluta para o grupo de tubarões e raias (A), para as diferentes espécies de Tubarões (B) e Raias (C) em função dos estratos batimétricos registrados nos desembarques pesqueiros da Pedra do Sal (PI) e que foram capturadas na APA do Delta do Parnaíba.

Tabela 4. Resultados da análise de similaridade de percentagens (SIMPER) entre as estações seca e chuvosa e os extratos batimétricos (I, II e III).

\begin{tabular}{c|c|c|c|c}
\hline Entre grupos (Raias) & Seca x Chuvosa & I x II & I x III & II x III \\
\hline Dissimilaridade média (\%) & 53 & 55 & 72 & 64 \\
\hline Espécies & \multicolumn{4}{|c}{ Contribuicão\% } \\
\hline H. guttatus & 26 & 25 & 27 & 29 \\
\hline H. americanus & 24 & 24 & 19 & 24 \\
\hline R. bonasus & 18 & 18 & 18 & 12 \\
\hline G. micrura & 16 & 18 & 11 & 16 \\
\hline Entre grupos (Tubarões) & Seca x Chuvosa & I x II & I x III & II x III \\
\hline Dissimilaridade média (\%) & 68 & 67 & 74 & 64 \\
\hline Espécies & \multicolumn{5}{|c|}{ Contribuição\% } & & \\
\hline R. porosus & 23 & 29 & 22 & 25 \\
\hline S. mokarran & 22 & 21 & 23 & 19 \\
\hline G. cirratum & 19 & 11 & 16 & 17 \\
\hline C. limbatus & 12 & 13 & 17 & 18 \\
\hline
\end{tabular}




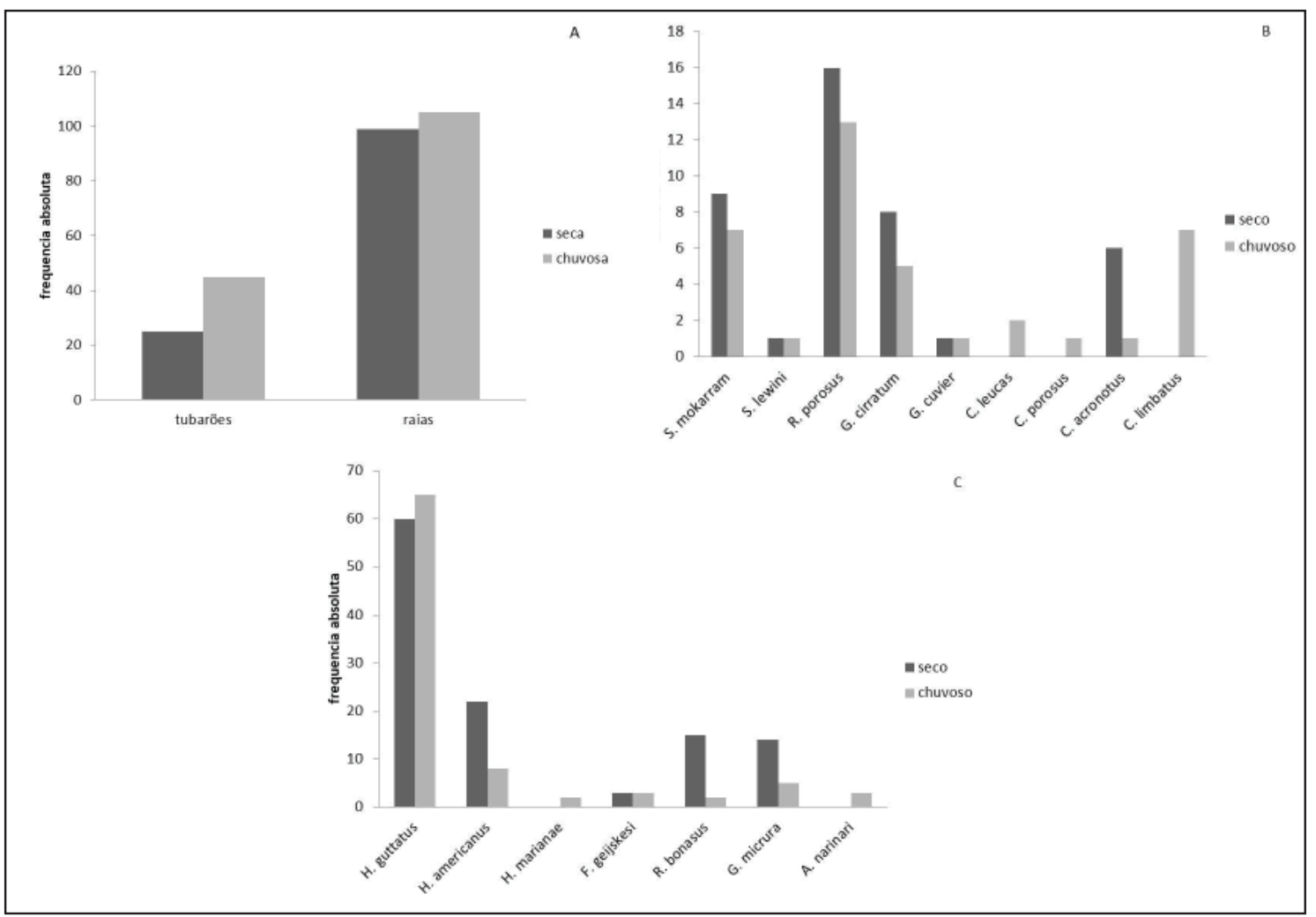

Figura 4. Distribuições de frequência absoluta de tubarões e raias (A), das diferentes espécies de Tubarões (B) e Raias (C) em função das estações (chuva e seca) registrados nos desembarques pesqueiros da Pedra do Sal (PI) e que foram capturadas na APA do Delta do Parnaíba .

ou seja, acima de 50\%. O segundo grupo era composto por A. narinari e H. marianae com cerca de $40 \%$ de similaridade entre as espécies (Figura 5). Para os tubarões, o teste SIMPROF $(p<0,05)$ indicou similaridade acima de $50 \%$ apenas entre $R$. porosus e S. mokarran. Para as outras espécies de tubarões a similaridade esteve abaixo de $40 \%$ (Figura 6).

A análise nMDS com os dados das raias, confirmou os resultados do Cluster, sendo o coeficiente de estresse $(<0,05)$ uma excelente representação, sem chances de conclusões equivocadas (Figura 7). O diagrama de Shepard com o comportamento exponencial da linha escalonada aos pontos, indicou a validade do nMDS (Figura 8).

O nMDS com os dados dos tubarões, também confirmou os resultados do Cluster, sendo o coeficiente de estresse $(<0,05)$ uma excelente representação, sem chances de conclusões equivocadas (Figura 9). O diagrama de Shepard com o comportamento exponencial da linha escalonada aos pontos, indicou a validade do nMDS (Figura 10).
Nenhuma diferença significativa foi observada na diversidade de Shannon-Wiener de raias e tubarões entre os extratos batimétricos (I, II e III), estações (seca e chuvosa) e nas interações (Tabelas 5 e 6 ).

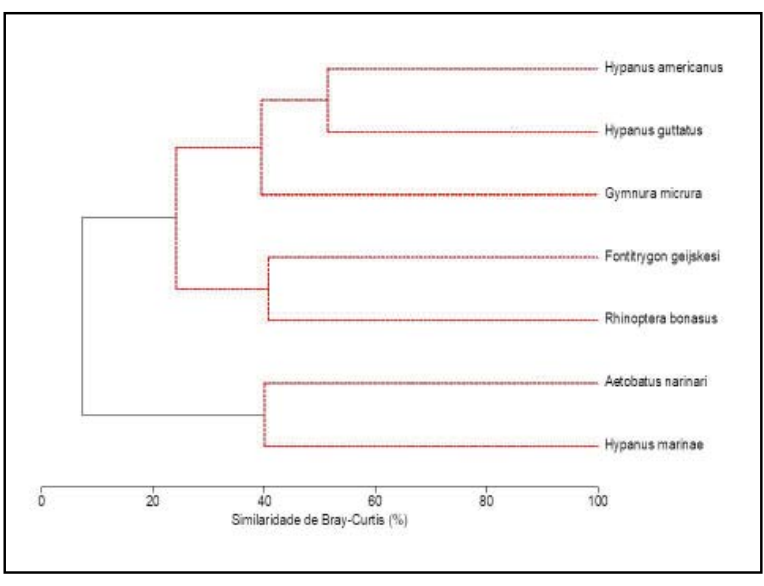

Figura 5. Dendograma baseado no número de raias capturadas pela pesca artesanal na APA do Delta do Paranaíba. As linhas pontilhadas indicam agrupamentos distintos de acordo com SIMPROF. 


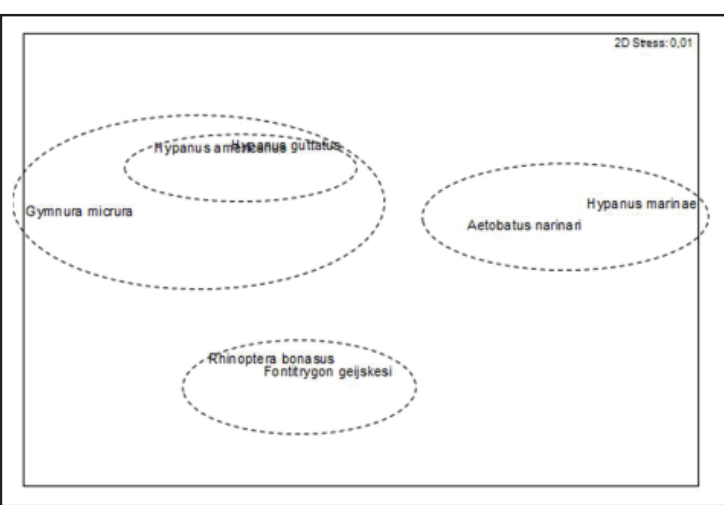

Figura 6. Expansão multidimensional não métrica (nMDS) com dados das raias capturadas pela pesca artesanal na APA do Delta do Paranaíba.

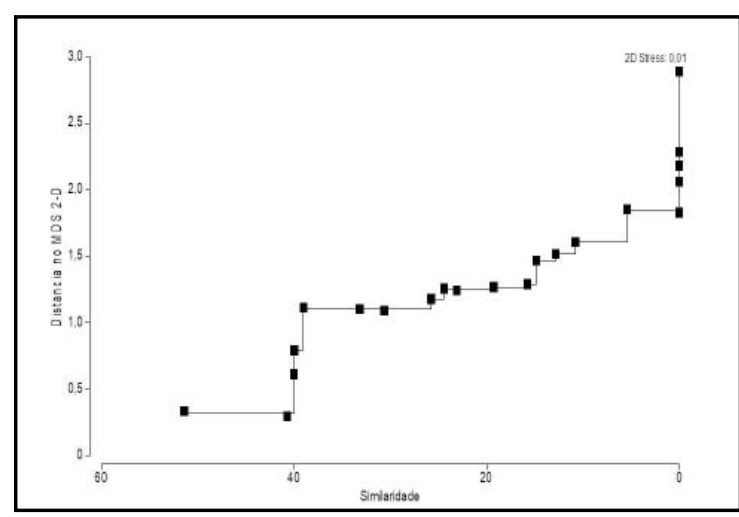

Figura 7. Diagrama de Shepard comparando em um gráfico de dispersão as distâncias euclidianas entre as espécies de raias, obtidas no MDS bidimensionalmente no eixo Y, com a similaridade de Bray-Curtis no eixo X.

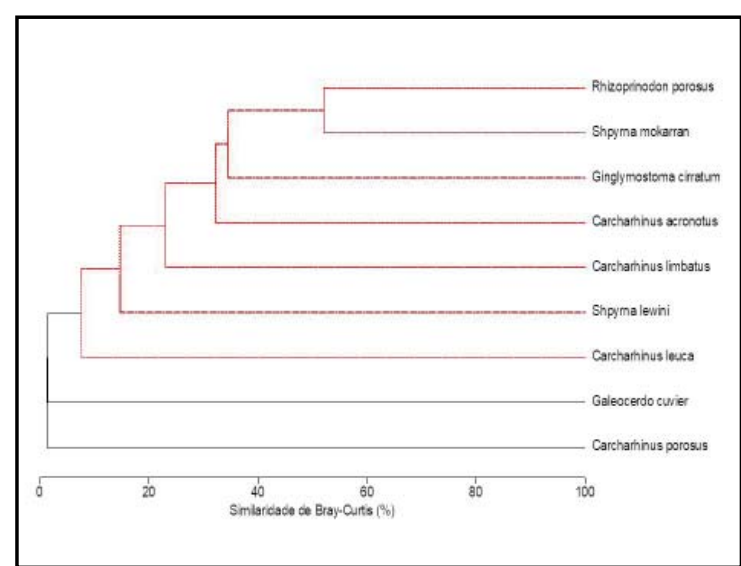

Figura 8. Dendograma baseado no número de tubarões capturados pela pesca artesanal na APA do Delta do Paranaíba. As linhas pontilhadas indicam agrupamentos distintos de acordo com SIMPROF.

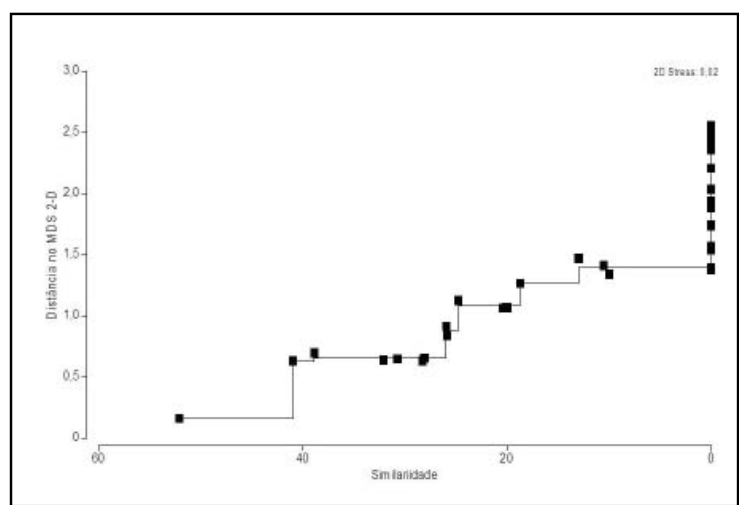

Figura 9. Expansão multidimensional não métrica (nMDS) com dados dos tubarões capturados pela pesca artesanal na APA do Delta do Paranaíba.

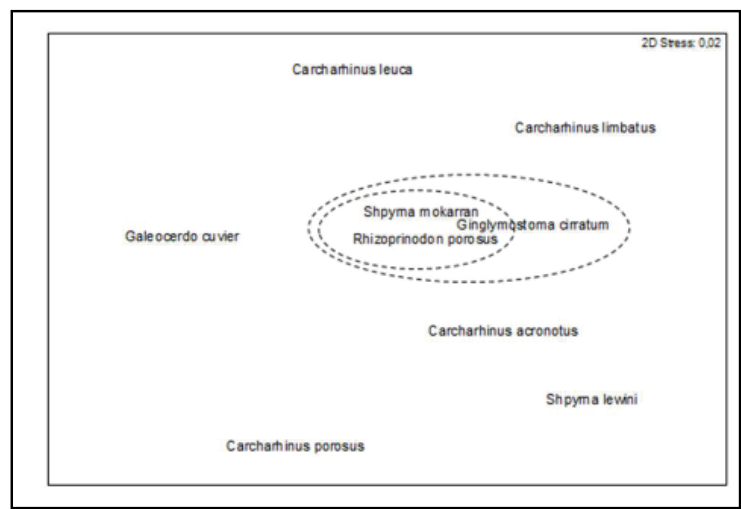

Figura 10. Diagrama de Shepard comparando em um gráfico de dispersão as distâncias euclidianas entre as espécies de tubarões, obtidas no MDS bidimensionalmente no eixo Y, com a similaridade de Bray-Curtis no eixo X.

Tabela 5. Resultados do teste PERMANOVA para a diversidade de Shannon-Wiener $\left(\mathrm{H}^{\prime}(\log \mathrm{e})\right)$ de raias entre os extratos batimétricos (A), estações (P) e interações. G1 = graus de liberdade e MS = soma dos quadrados médios.

\begin{tabular}{ccccc}
\hline $\begin{array}{c}\text { Fonte de variação } \\
\text { para raias }\end{array}$ & Gl & MS & Pseudo-F & P (perm) \\
\hline $\begin{array}{c}\text { Extratos } \\
\text { batimétricos (A) } \\
\text { Estações (P) }\end{array}$ & 2 & 195,1 & 0,8439 & 0,447 \\
\hline A x P & 2 & 85,3 & 0,0273 & 0,922 \\
\hline Resíduo & 16 & 231,2 & 0,3703 & 0,727 \\
\hline
\end{tabular}


Tabela 6. Resultados do teste PERMANOVA para a diversidade de Shannon-Wiener $\left(\mathrm{H}^{\prime}(\log \mathrm{e})\right)$ de tubarões entre os extratos batimétricos (A), estações (P) e interações. $\mathrm{Gl}=$ graus de liberdade e MS = soma dos quadrados médios.

\begin{tabular}{ccccc}
\hline $\begin{array}{c}\text { Fonte de variação } \\
\text { para tubarões }\end{array}$ & GI & MS & Pseudo-F & P (perm) \\
\hline $\begin{array}{c}\text { Extratos } \\
\text { batimétricos (A) } \\
\text { Estações (P) }\end{array}$ & 2 & 397,8 & 0,4525 & 0,840 \\
\hline A x P & 2 & 650,3 & 0,5122 & 0,656 \\
\hline Resíduo & 10 & 879,2 & 0,7527 & 0,441 \\
\hline
\end{tabular}

\section{DISCUSSÃO}

O presente estudo identificou nove espécies de tubarões e sete de raias em diferentes categorias de estado de conservação, segundo os critérios de avaliação da IUCN. Considerando as avaliações efetuadas a nível nacional (ICMBio, 2016), das dezesseis espécies de elasmobrânquios identificadas, somente uma encontrava-se no nível menos preocupante de ameaça (LC) e seis apresentavam déficit de informações para uma avaliação do seu estado de conservação (DD).

Dulvy et. al., (2014), quando em estudo realizado sobre o risco de extinção e conservação de tubarões e raias no mundo, previram que mais da metade das espécies classificadas como DD apresentavam algum risco de ameaça. Nesse sentido, pode-se considerar que as espécies de elasmobrânquios mais capturadas ( $R$. porosus (DD) e H. guttatus (LC)) podem estar em categorias equivocadas. Esse tipo de divergência pode contribuir para uma gestão pesqueira ineficiente e declínio de espécies que podem estar sobre-explotadas.

O tubarão $R$. porosus se tornou a espécie mais frequente nos desembarques da região norte do Brasil após o declínio nas capturas de outros elasmobrânquios costeiros, como é o caso do $C$. porosus, espécie que registrou a menor frequência de ocorrência para a APA do Delta. Com isso, acredita-se que $R$. porosus possa estar enfrentando uma pressão da pesca crescente na região costeira, sua principal área de distribuição (Lessa et al., 2006).

O C. porosus, espécie considerada criticamente em perigo em águas brasileiras desde 2012, alcançou essa condição devido à sobrepesca de indivíduos em fase de juvenil, em conjunto com a baixa taxa de fecundidade (Lessa et al., 2006). Na década de 80 a espécie compunha $80 \%$ da pesca de elasmobrânquios com rede de emalhe no estado do Maranhão, sendo desses $43 \%$ juvenis. Mais recentemente se registra uma restrição de áreas de ocorrência, sendo observada somente em regiões mais distantes da costa (Elias, 2004; Tavares et al., 2005).

Mesmo ameaçados a nível nacional, os tubarões S. mokarran (CR) e G. cirratum (VU) fazem parte das espécies de tubarões mais capturadas na APA do Delta, totalizando uma frequência de $36 \%$. S. mokarran além de se reproduzir uma vez a cada dois anos, é considerado de hábito solitário, o que aumenta a sua vulnerabilidade à pesca como captura incidental (Dudley \& Simpfendorfer, 2006). No Atlântico Oriental, a ausência de registros recentes leva a suspeitar uma diminuição populacional de $S$. mokarran em pelo menos $80 \%$ nos últimos 25 anos (Denham et al., 2007). Por sua vez, G. cirratum já é considerado extinto em algumas áreas da porção sul do Atlântico Ocidental. Sua distribuição costeira, comportamento gregário em ambientes rochosos, recifes de coral, naufrágios e fidelidade às áreas de descanso, aumentam as suas chances de captura (Castro \& Rosa, 2005; Rosa et. al., 2006).

Os demais tubarões registrados $(28 \%$ das ocorrências), representados por C. leucas (NT), G. cuvier (NT), C. acronotus (NT), C. limbatus (NT) e S. lewini (CR) potencialmente, por serem de hábitos costeiros e de grande porte, aumentam a sua capturabilidade as artes de pesca artesanais, como é o caso do emalhe e o seu de risco de extinção (Dulvy et al., 2014). Sofrem intensa pressão pesqueira ao longo de sua faixa de ocorrência, desde as áreas de berçário em profundidades menores que $20 \mathrm{~m}$, até a quebra da plataforma continental. Estas espécies também devem ser constantemente monitoradas, já que o seu estado de conservação pode mudar ao longo do tempo, como reflexo da pesca e da degradação ambiental das zonas costeiras (Baum et. al., 2007; Burgess \& Branstetter, 2009; Morgan et. al., 2009; Simpfendorfer, 2009; Simpfendorfer \& Burgess, 2009; Kotas et al. 2012).

Duas espécies de tubarões ocorreram exclusivamente na estação chuvosa, i.e. C. leucas e C. porosus, havendo necessidade de um maior número de dados para confirmar essa tendência. Entretanto, estudos demonstram que o C. leucas do hemisfério Sul têm a época de parto entre novembro e fevereiro (Sadowsky, 1971), período de chuvas para a região estudada.

A família Carcharhinidae foi a mais frequente durante o período estudado, com seis espécies identificadas. Lessa (1997) relatou que $77 \%$ de cinquenta e quatro capturas realizadas na costa ocidental do Maranhão são de espécies pertencentes a família Carcharhinidae. Compagno (1990) cita que, em um habitat favorável, os tubarões da ordem 
Carcharhiniformes - que no caso incluem a famílias Carcharhinidae e Sphyrnidae, apresentam um sucesso competitivo superior às outras.

As raias que apresentaram maior ocorrência na APA do Delta do Parnaíba, $H$. guttatus e $H$. americanus, são categorizadas a nível nacional como de menor preocupação (LC) e com deficiência de dados (DD) respectivamente, necessitando de mais estudos no país. A abundância de Hypanus guttatus na APA do delta do Parnaíba pode se dar devido à preferência por ambientes lamosos ou arenosos, como relatado para outras regiões com características semelhantes (Figueiredo, 1977; Furtado-Neto \& Pinto, 2002; Rosa \& Furtado, 2016a). A maior frequência da $H$. guttatus corrobora com Nunes et al. (2005) que reportaram a espécie como a mais abundante no litoral maranhense sem padrão sazonal de ocorrência. Já $H$. americanus é uma espécie estuarina, tendo preferência por ambientes associados a bancos de algas marinhas e recifes coralinos (Grubbs et. al., 2016).

A raia de menor frequência na APA do Delta do Parnaíba foi $H$. marianae $(<1 \%)$, que apresenta maior grau de endemismo e déficit de dados em seu status de conservação (DD). Recentemente, através da avaliação das ameaças a peixes recifais no Brasil, foi atribuída $75 \%$ de probabilidade da espécie se tornar ameaçada (Bender et al., 2013). Acredita-se que a mesma esteja concentrada do Maranhão ao Sul da Bahia (Rosa \& Furtado, 2016b). De acordo com Gomes et al. (2000), H. marianae vive associada a ambientes recifais costeiros. Não apresenta valor comercial no APA do Delta do Parnaíba, sendo geralmente descartada após a captura e os níveis de mortalidade por pesca são desconhecidos.

As demais raias registradas na APA, com frequência de $24,1 \%$, foram $F$. geijskesi (DD), $R$. bonasus (DD), G. micrura (NT) e A. narinari (DD). Com exceção de $A$. narinari, as demais espécies foram também registradas por Nunes et al., (2005) em águas rasas do Maranhão, podendo ser encontradas em águas costeiras de fundos arenosos ou lamosos e no caso de A.narinari associada a recifes de coral (Cervigón et al., 1992; Barker, 2006; Charvet-Almeida \& Almeida, 2016; Grubbs \& Em, 2006; Kyne et. al., 2006; Goodman et al., 2010; Ajemian \& Powers, 2016; Rangel et al., 2018; McEachran \& Carvalho, 2002; Richards et al., 2009).

As raias têm uma função ecológica importante nas cadeias tróficas de comunidades bentônicas e demersais, como é o caso da APA do Delta do Parnaíba, sendo o elo entre os predadores de topo e os níveis basais de uma cadeia alimentar (Mabragaña et al. 2005; Heithaus et al. 2008; Bornatowski 2014).
Suas estratégias de vida, ou seja, baixa fecundidade e reprodução tardia as tornam vulneráveis as atividades pesqueiras (Visintin 2012; Barausse et al. 2014). De acordo com Dulvy \& Reynolds (2002) as espécies de raias que desapareceram de suas áreas de distribuição, atingiam tamanhos corporais maiores. Estudos comparativos indicam que espécies de maior porte, tendem a sofrer maiores declínios do que as de menor tamanho (Jennings et al. 1998, 1999a; Dulvy et al. 2000; Stevens et al., 2000). Portanto, existe uma correlação positiva entre o tamanho corporal e a tendência ao declínio populacional (Walker \& Hislop, 1998; Dulvy et al. 2000). Existem vários exemplos de extinção local de raias, ou seja, Dipturus laevis, D. batis, D. oxyrhinchus e Rostroraja alba e, portanto, há necessidade de medidas precaucionais para conservar e estudar em mais detalhes as raias que ocorrem na APA do Parnaíba e sua interação com as atividades pesqueiras (Dulvy et al. 2000; Dulvy \& Reynolds 2002).

As análises de Cluster e NMDS evidenciaram similaridades nas associações de certas espécies de tubarões (i.e. R. porosus e S. mokarran) e raias (i.e. $H$. guttatus e H. americanus) na APA do Parnaíba quanto ao uso dos extratos batimétricos. Essas similaridades nas associações poderiam ser explicadas pelo uso das áreas para alimentação, onde ocorre a competição pelos alimentos, a exemplo dos tubarões $R$. porosus e $S$. mokarran, que têm a alimentação semelhante, constituída principalmente por pequenos peixes teleósteos e também lulas, caranguejos e camarões (Silva \& Almeida, 2018). Já no caso das raias $H$. gutattus e $H$. americanus, estas competem pelos mesmos recursos, alimentando-se de pequenos invertebrados, principalmente crustáceos (Grubbs et al., 2016).

Os dados aqui apresentados reforçam a importância da APA do Delta do Parnaíba como área de uso de elasmobrânquios, inclusive de espécies com importância comercial (i.e. R. porosus) e/ou consideradas ameaçadas de extinção pela legislação brasileira (i.e. G. cirratum), a exemplo do que ocorre em outras Unidades, como no Sítio Ramsar e Parque Estadual Marinho Parcel Manoel Luís no estado do Maranhão (Motta et al., 2009). Os diversos tipos de uso das áreas na APA pelas espécies de tubarões e raias precisam ser melhor entendidos, por meio de estudos mais detalhados sobre dinâmica populacional, reprodução, alimentação e comportamento.

A maior presença dos tubarões $R$. porosus, $S$. mokarran, G. cirratum, C.acronotus, das raias $H$. americanus, $R$. bonasus, G. micrura no período seco e do tubarão C. limbatus e da raia H.guttatus no período chuvoso evidenciou a importância de um 
fenômeno climático sazonal regional (chuva/seca) na dinâmica de ocorrência das diferentes espécies de elasmobrânquios na APA do Delta do Parnaíba. Esse fenômeno já havia sido observado por Martins (2015) no litoral do Maranhão. De acordo com Kottek et al. (2006), a costa do Piauí apresenta o clima predominante $A w /$ Equatorial com inverno seco. Há um período chuvoso (janeiro - junho) e outro seco (julho - dezembro). De acordo com Martins (2015) a presença de tubarões na costa do município de Tutóia (MA) foi mais frequente nos períodos secos. Neste caso, as espécies capturadas com maior frequência foram Rhizoprionodon porosus, Carcharhinus acronotus, Sphyrna spp., Carcharhinus limbatus, Galeocerdo cuvier, Ginglymostoma cirratum e Carcharhinus leucas, composição de fauna semelhante à encontrada no presente estudo. Também durante o período de seca, principalmente nos meses de novembro e dezembro, Martins (2015) encontrou fêmeas prenhes e muitos filhotes de Carcharhinus limbatus, na praia de Tutóia, diferindo das maiores ocorrências desta espécie no período chuvoso para o presente estudo. Entretanto, em especial para esta espécie, há necessidade de um número maior de informações para se chegar a conclusões adequadas.

O estudo em questão é de grande importância para a APA do Delta do Parnaíba, devido a sua contribuição como um diagnóstico inicial da elevada diversidade de espécies de elasmobrânquios que utilizam essa região em alguma fase do seu ciclo de vida, seja por questões alimentares, reprodutivas ou até mesmo comportamentais, e da importância da batimetria e do regime de chuvas nessa dinâmica espaço-temporal. Assim, o presente estudo levanta importantes informações em uma região extremamente carente de conhecimento. Obviamente há necessidade de estudos mais detalhados e continuados sobre a biologia e dinâmica populacional das espécies, sua interação com a pesca artesanal costeira, bem como dos efeitos das variáveis ambientais sobre o comportamento e o ciclo de vida das mesmas.

No Plano de Manejo dessa APA é importante que seja inserido o monitoramento continuado das pescarias artesanais que capturam os elasmobrânquios. Sem um programa detalhado de entrevistas com os pescadores, amostragem biológica nos desembarques e quando possível acompanhamento as operações de pesca, não há como obter subsídios técnicos para que sejam estabelecidas medidas de gestão pesqueira visando a sustentabilidade das pescarias, bem como a recuperação e conservação de espécies ameaçadas na APA. O monitoramento ambiental também é de extrema importância, já que as variáveis como pluviosidade, força das marés, temperatura da água, salinidade, nutrientes, tipo de fundo e dos níveis de oxigênio dissolvido, influenciam na distribuição e abundância das espécies e na qualidade do ecossistema.

Segundo Dulvy et al. (2014), o risco de extinção de uma determinada espécie aumenta com o seu tamanho corporal e proximidade da costa. Desta forma, ao compararmos as espécies encontradas na APA do Delta do Parnaíba com os seus tamanhos máximos e distribuição batimétrica (tabela 6), espécies avaliadas como NT (como é o caso de C. leucas, C. limbatus e C. acronotus) e VU (G. cirratum) podem estar em níveis mais elevados de ameaça, por serem espécies costeiras e de grande porte, ou seja mais propensas à captura pelas artes de pesca. Situação semelhante pode estar ocorrendo com as raias avaliadas como DD (A. narinari, $R$. bonasus e $H$. americanus), e também com $H$. guttatus avaliada como LC.

Segundo Primack \& Rodrigues (2002), a solução para se manejar e proteger espécies ameaçadas ou que sejam detentoras de um potencial risco de declínio populacional como os elasmobrânquios, é entender suas relações ecológicas e o estado atual de conservação da sua população. Nesse mesmo contexto, Simpfendorfer \& Dulvy (2017) sugerem que, para a maioria ou para todas as populações de elasmobrânquios, é necessário um diagnóstico e gestão específica para cada espécie, em vez de serem promovidas soluções mais simplificadas como a proibição da pesca. Assim, acredita-se que os benefícios serão tanto para a conservação da biodiversidade, quanto para a sustentabilidade da pesca e segurança alimentar.

\section{AGRADECIMENTOS}

A CAPES pela bolsa de doutorado concedida; ao CEPSUL pelo apoio intelectual.

\section{REFERÊNCIAS}

AJEMIAN , M. J, POWERS, S. P. 2016. Seasonality and ontogenetic habitat partitioning of cownose rays in the Northern Gulf of Mexico. Estuaries Coast.: 39(4):1234-48.

AMORIM, M. C., NUNAN, G. W. A., \& SENNA, M. L. (2002). Extinção das populações de peixesserra (Chondrichthyes, Rajiformes) no estado do Rio de Janeiro, Brasil (342 p.). Resumos do XXIV Congresso Brasileiro de Zoologia, 24.

ANDERSON, C. \& WAHEED, A. 2001. The economics of shark and ray watching in the 
Maldives. Shark News 13:1-3.

BASILIO, T. H.; FARIA, V. V. FURTADO-NETO, M. A. 2008. Fauna de elasmobrânquios do estuário do rio Curu, Ceará, Brasil. Arquivos de Ciências do Mar, Fortaleza, v. 41, n. 2, p. 65-72.

BARAUSSE, A.; CORREALE, V.; CURKOVIC, A.; FINOTTO, L. \& RIGINELLA, E. 2014. The role of fisheries and the environment in driving the decline of elasmobranchs in the northern Adriatic Sea. ICES Journal of Marine Science; doi: 10.1093/ icesjms/fst222.

BARKER, A. S. Rhinoptera bonasus. The IUCN Red List of Threatened Species 2006: e.T60128A12310195. http://dx.doi.org/10.2305/ IUCN.UK.2006.RLTS.T60128A 12310195. en. Downloaded on 23 August 2017.

BAUM, J., CLARKE, S., DOMINGO,A., DUCROCQ, M., LAMÓNACA, A.F., GAIBOR, N., GRAHAM, R., JORGENSEN, S., KOTAS, J.E., MEDINA, E., MARTINEZ-ORTIZ, J., MONZINI TACCONE DI SITIZANO, J., MORALES, M.R., NAVARRO, S.S., PÉREZ-JIMÉNEZ, J.C., RUIZ, C., SMITH, W., VALENTI, S.V. \& VOOREN, C.M. Sphyrna lewini. The IUCN Red List of Threatened Species 2007: e.T39385A10190088. http://dx.doi.org/10.2305/ IUCN.UK.2007.RLTS.T39385A 10190088. en. Downloaded on 22 August 2017.

BENDER, M.G., FLOETER, S.R., MAYER, F.P., VILA- NOVA, D.A, LONGO, G.O., HANAZAKI, N., CARVALHO- FILHO, A. AND FERREIRA, C . E . L. 2013. Biological attributes and major threats as predictors of the vulnerability of species: a case study with Brazilian reef fishes. Orix, 47, 259-265.

BORNATOWSKI, H. \& ABILHOA, V. 2012. Tubarões e raias capturados pela pesca artesanal no Paraná: guia de identificação. Curitiba, Hori Consultoria Ambiental. Hori Cadernos Técnicos $n^{\circ}$ 4. 124 pp. .

BORNATOWSKI, H. 2014. Importância ecológica dos tubarões e raias em uma rede trófica na costa sul do Brasil. Tese de doutorado. Universidade Federal do Paraná. 116 pp.

BURGESS, H. G. \& BRANSTETTER, S. Carcharhinus limbatus. The IUCN Red List of Threatened Species 2009: e.T3851A10124862. http:// dx.doi.org/10.2305/IUCN.UK.2009-2.RLTS. T3851A10124862.en. Downloaded on 22 August 2017.

BURGESS, G.H.; CARVALHO, J.F. \& IMHOFF, J.L. 2009. An evaluation of the status of the largetooth sawfish, Pristis perotteti, based on historic and recent distribution and qualitative observations of abundance. Florida Museum of Natural History Report.

CASTRO, A.L.F. AND ROSA, R.S.2005. Use of natural marks on population estimates of the nurse shark, Ginglymostoma cirratum, at Atol das Rocas Biological Reserve, Brazil. Environ Biol of Fishes, 72(2): 213-221.

CENTRO DE HIDROGRAFIA DA MARINHA (CHM): Temperatura da superfície do mar. https:// www.mar.mil.br/dhn/chm/meteo/. Accessed 20 Oct. 2014.

CERVIGÓN, F.; CIPRIANI, R.; FISCHER, W.; GARIBALDI, L.; HENDRICKX, M.; LEMUS, A.J.; MÁRQUEZ, R.; POUTIERS, J. M.; ROBAINA, G. ANDRODRIGUEZ, B. 1992. Fichas FAO de identificación de especies para los fines de la pesca. Guía de campo de las especies comerciales marinas y de águas salobres de la costa septentrional de Sur América. FAO, Rome. 513 p. Preparado con el financiamento de la Comisión de Comunidades Europeas y de NORAD.

CHARVET-ALMEIDA，P. 1999. General information from Sawfishes in Pará State, north Brazil. Boletim SBEEL, 4: 12.

C H A R V E T - A L M E I D A , P. \& DE ALMEIDA, M.P. Fontitrygon geijskesi. The IUCN Red List of Threatened Species 2016: e.T60153A104171793. http://dx.doi.org/10.2305/ IUCN.UK.20163.RLTS.T60153A 104171793. en. Downloaded on 23 August 2017.

CHEUNG, W. W., LAM, V. W., SARMIENTO, J. L., KEARNEY, K., WATSON, R., PAULY, D. 2009. Projecting global marine biodiversity impacts under climate change scenarios. Fish and Fisheries, 10(3), 235-251.

CLARKE, K. R.; GORLEY, R. N. 2006. PRIMER v6.1.6. User Manual/Tutorial: PRIMER-E, Plymouth Marine Laboratory.

CLARK, K. R.; WARWICK, R. W. 1994. Change in marine communities: an approach to statistical analysis and interpretation. Plymouth: Plymouth Marine Laboratory. 859p.

COMPAGNO, L. J. V. 1990. Shark exploitation and conservation. In: Pratt, H. L., Gruber, S. H., Taniuchi, T., editors. Elasmobranchs as living resources: advances in the biology, ecology, systematics, and the status the fisheries. NOAA Technical Report NMFS, 90: 397- 414. 
COMPAGNO, L. J. V. 2005. Checklist of living Chondrichthyes In> Hamlett, W. C. (ed) Reproductive of Chondrichthyes sharks, rays and chimaeras, Vol. 3. Endfiled, USA: Science Publishers; 503- 548. Compagno, L, Dando, M and Fowler, S. 2005. A field Guide to the Sharks of the World. Harper-Collins, London, $368 \mathrm{pp}$.

CUEVAS, E.; PÉREZ, J. C.; MÉNDEZ, I. 2013. Efecto de fatores ambientales y la asignación del esfuerzo pesquero sobre las capturas de la raya Aetobatus narinari (Rajiformes: Myliobatidae) en el sur del Golfo do México. Em. Biol. Trop. 61, (3), 1341-1349.

DENHAM, J., STEVENS, J.D., SIMPFENDORFER, C., HEUPEL, M.R., CLIFF, G., MORGAN, A., GRAHAM, R., DUCROCQ, M., DULVY, N.K., SEISAY, M., ASBER, M., VALENTI, S.V., LITVINOV, F., MARTINS, P., LEMINE OULD SIDI, M., TOUS, P. \& BUCAL, D. Sphyrna mokarran. The IUCN Red List of Threatened Species 2007:e. T39386A10191938. http://dx.doi.org/10.2305/ IUCN.UK.2007.RLTS.T39386A 10191938. en. Downloaded on 19 July 2017.

DENT, F. \& CLARKE, S. 2015. State of the global market for shark products. FAO Fisheries and Aquaculture Technical Paper, 590.

DEPARTAMENTO DE HIDROGRAFIA E NAVEGAÇÃO (DHN): Tábua de marés para 2014 - costa do Brasil e alguns portos estrangeiros. http:// www.mar.mil.br/dhn/chm/box-previsao-mare/ tabuas/. Accessed 20 Oct 2014.

DIAS NETO, J. 2011. Proposta de Plano Nacional de Gestão para o uso sustentável de elasmobrânquios sobre-explotados ou ameaçados de sobre-explotação no Brasil / José Dias Neto, Organizador. - Brasília: Ibama.

Dias-Neto, J. 2015. O uso da Biodiversidade aquática no Brasil: uma avaliação com foco na pesca. Brasília: Ibama. 288p.

DUDLEY, S.F.J. \& SIMPFENDORFER, C.A. 2006. Population status of 14 shark species caught in the protective gillnets off KwaZulu-Natal beaches, South Africa, 1978-2003. Marine Freshw Resear, 57: 225-240.

DULVY,N. K.; J.D. METCALFE; J. GLANVILLE; M. G. PAWSON \& J. D. REYNOLDS. 2000. Fishery stability, local extinctions and shifts in community structure in skates. Conservation Biology 14: 283-293.

DULVY, N.K. \& REYNOLDS, J.D. 2002.
Predicting Extinction Vulnerability in Skates. Conservation Biology. Volume 16, No. 2, 440-450.

DULVY, N. K., BAUM, J. K., CLARKE, S., COMPAGNO, L. J., CORTES, E., DOMINGO, A., MARTÍNEZ, J. 2008. You can swim but you can't hide: the global status and conservation of oceanic pelagic sharks and rays. Mar and Freshwr Ecosys, 18(5), 459-482.

DULVY, N.K., FOWLER, S.L., MUSICK, J.A., CAVANAGH, R.D., KYNE, P.M., HARRISON, L.R., CARLSON, J.K., DAVIDSON, L.N.K., FORDHAM, S.V., FRANCIS, M.P., POLLOCK, C.M., SIMPFENDORFER, C.A., BURGESS, G.H., CARPENTER, K.E., COMPAGNO, L.J.V., EBERT, D.A., GIBSON, C., HEUPEL, M.R., LIVINGSTONE, S.R., SANCIANGCO, J.C., STEVENS, J.D., VALENTI, S., WHITE, W.T. 2014. Extinction risk and conservation of the world's sharks and rays. $2014 \mathrm{http}: / / \mathrm{dx}$.doi.org/10.7554/eLife.00590

ELIAS, M. P. P. 2004. Diagnóstico da pesca de elasmobrânquios oriundos da costa norte brasileira e desembarcados nos portos da região Bragantina (Pará). In: IV Reunião SBEEL: A busca da sustentabilidade pesqueira de elasmobrânquios no Brasil, SBEEL (Sociedade Brasileira para o Estudo de Elasmobrânquios), Recife, Bagaço, v. vol. únic.: 66-67.

FARIA, V.V., CHARVET-ALMEIDA, P. 2008. Pristis pectinata (v. II, pp. 31-33). In: Machado, A. B. M., Drummond, G. M., \& Paglia, A. P. (Org.). Livro Vermelho da Fauna Brasileira Ameaçada de Extinção. Brasília, DF: Ministério do Meio Ambiente e Fundação Biodiversitas.

FEITOSA L.M.F., LESSA R.P.T., MARTINS, A.P.B., BARBIERI R. \& NUNES, J.L. 2018. Daggernose Shark: na elusive species from Northern South America. Doi: 10.1002/fsh. 10205.

FERREIRA A.C. \& L.D. LACERDA. 2016. Degradation and conservation of Brazilian mangroves, status and perspectives. Ocean \& Coastal Management 125: 38-46.

FERRETTI F., MYERS R.A., SERENAF. \& LOTZE H. K. 2008. Loss of large predatory sharks from the Mediterranean Sea. Conservation Biology, Volume 22, No 4, 952-964. Doi: 10.1111/j. 1523-1739.2008. 00938.x

FERRETTI, F., WORM, B., BRITTEN, G. L., HEITHAUS, M. R. AND LOTZE, H. K. 2010. Patterns and ecosystem consequences of shark declines in the ocean. Ecology Letters, 13, 10551071. 
FIGUEIREDO, J.L. 1977. Manual de Peixes Marinhos do Sudeste do Brasil I. Introdução, Cações, raias e quimeras. São Paulo: Museu de Zoologia Universidade de São Paulo.

FISCHER, A. F. Hazin, FHV., Carvalho, F. Viana, DL., Rêgo, MG., Wor, C. 2009. Biological aspects of sharks caught off the Coast of Pernambuco, Northeast Brazil. Braz. J. Biol., v. 69, n. 4, p. 1173-1181.

FONSECA, C.A., PATTI, J.R., CAMPOS, E.J.D., SILVEIRA, I.C.A. 2000. Estudo numérico dos vórtices emitidos pela corrente norte do Brasil. São Paulo: Laboratório de Modelagem dos Oceanos.

FONTELES-FILHO, A. A. 2011. Oceanografia, biologia e dinâmica populacional dos recursos pesqueiros. Expressão gráfica e Editora, Fortaleza, $464 \mathrm{p}$.

FURTADO-NETO, M.A. \& PINTO, L.J.B. 2002. Identificação de áreas de berçário da raia Dasyatis guttata (Dasyatidae; Elasmobranchii), em poças de maré do litoral do Ceará. João Pessoa, In: Summaries of the III Meeting of the SBEEL. Pp: 40-41.

GILLIAM, D. and SULLIVAN, K. M. 1993. Diet and feeding habits of the southern stingray Dasyatis americana in the central Bahamas. Bull. Mar. Sci. 52(3): 1007-1013.

GOODMAN MA, CONN PB, FITZPATRICK E. 2010. Seasonal occurrence of cownose rays (Rhinoptera bonasus) in North Carolina's estuarine and coastal waters. Estuaries Coast; 34(3):640-51.

GOMES, U.L., ROSA, R.S. \& GADIG, O.B.F. 2000. Dasyatis macrophthalma sp. n.: a new species of stingray (Chondrichthyes: Dasyatidae) from the southwestern Atlantic. Copeia (2): 510-515.

GONÇALVES, A.P., DOURADO, E.C. dos S., CASTRO, A.C.L. \& TAVARES, R.G.C.de F. 2003. Aspectos da dinâmica populacional da serra, Scomberomorus brasiliensis (Teleostei, Scombridae), no Estado do Maranhão, Brasil. Boletim do Laboratório de Hidrobiologia, 16: 37-46.

GRUBBS, R.D. \& EM, D.S. Gymnura micrura. The IUCN Red List of Threatened Species 2006:e. T60115A12305055. http://dx.doi.org/10.2305/ IUCN.UK.2006.RLTS.T60115A 12305055. en. Downloaded on 23 August 2017.

GRUBBS, R.D., SNELSON, F.F., PIERCY,A., ROSA, R. \& FURTADO, M. 2016. Hypanus americanus. The IUCN Red List of Threatened Species 2016: e.T60149A104123038.http://dx.doi.org/10.2305/ IUCN.UK.20163.RLTS.T60149A 104123038. en. Downloaded on 20 July 2017.
HAZIN, F.H.V., BURGESS, G. H. AND CARVALHO, F.C. 2008. A shark attack outbreak off Recife, Pernambuco, Brasil: 1992- 2006. Bull Mar Sci 82: 199-212.

HEITHAUS M.R., FRID A., WIRSING A.J. AND WORM B. 2008. Predicting ecological consequences of marine top predator declines. Trends in Ecology and Evolution 23(4), 202-210.

HOYOS-PADILLA, E. M., KETCHUM, J. T., KLIMLEY, A. P. \& GALVÁN-MAGAÑA, F. 2014. Ontogenetic migration of a female scalloped hammerhead shark Sphyrna lewini in the Gulf of California. Animal Biotelemetry 2,17.

IBAMA - INSTITUTO BRASILEIRO DO MEIO AMBIENTE E DOS RECURSOS NATURAIS RENOVÁVEIS. 1998. Plano de gestão e diagnóstico Geoambiental e socioeconômico da APA do delta do Parnaíba/IBAMA, Ministério do Meio Ambiente, recursos Hídricos e da Amazônia Legal. Fortaleza: IEPS/UECE.

IBAMA - INSTITUTO BRASILEIRO DE MEIO AMBIENTE E DOS RECURSOS NATURAIS RENOVÁVEIS. 2011. Proposta de plano de gestão para o uso sustentável de Elasmobrânquios sobreexplotados ou ameaçados de sobre-explotação no Brasil. Brasília. 154p.

ICMBio/MMA. 2016. Avaliação do risco de extinção dos elasmobrânquios e quimeras no Brasil: 2010-2012. Disponível em: http://www. icmbio.gov.br/cepsul/images/stories/biblioteca/ download/trabalhos_tecnicos/pub_2016_avaliacao_ elasmo_2010_2012.pdf

ICMBio/MMA, 2018. Livro Vermelho da Fauna Brasileira Ameaçada de Extinção: Volume VI Peixes / -- 1. ed. -- Brasília, DF, 7 v.: il.

JENNINGS, S., J. D. REYNOLDS, AND S. C. MILLS. 1998. Life history correlates of responses to fisheries exploitation. Proceedings of the Royal Society of London, Series B 265:333-339.

JENNINGS, S.; J. D. REYNOLDS; \& N. V. C. POLUNIN. 1999a. Predicting the vulnerability of tropical reef fishes to exploitation: an approach based on phylogenies and life histories. Conservation Biology 13:1466-1475.

KOTAS, J.E., PETRERE JR, M., DOS SANTOS, R.A., BUSTAMANTE, A., LIN, C.F., MENEZES, A.A.S., MICHELETTI, E.L.V. 2012. The horizontal migration of hammerhead sharks along the southern Brazilian coast, based on their exploitation pattern and considerations about the impact of anchored 
gillnets activities on these species. Revista CEPSUL - Biodiversidade e Conservação Marinha 3(1):4568pp.

KOTTEK, M., GRIESER, J., BECK, C., RUDOLF, B., RUBEL, F. 2006. World map of the Köppen-Geiger climate classification updated. Meteorol Zeitschrift, 15: 259-63. doi: 10.1127/0941-2948/2006/0130.

KRUSKAL, J. B. 1964. Nonmetric Multidimensional Scaling: a numerical method. Psychometrica, 2: 115-129.

KYNE, P.M., ISHIHARA, H, DUDLEY, S.F.J. \& WHITE, W.T. Aetobatus narinari. The IUCN Red List of Threatened Species 2006: e.T39415A10231645. http://dx.doi.org/10.2305/ IUCN.UK.2006.RLTS.T39415A 10231645. en. Downloaded on 23 August 2017.

LESSA, R.T. 1986. Levantamento faunístico dos elasmobrânquios do litoral ocidental do Estado do Maranhão, Brasil. Boletim do Laboratório de Hidrobiologia, São Luis, MA, 7: 27-42.

LESSA, R. P. 1997. Sinopse dos estudos sobre elasmobrânquios da costa do Maranhão. Bol. Lab. Hidrobio., v. 10, n. 1: 19-36.

LESSA, R., BATISTA, V., \& ALMEIDA, Z. 1999. Occurrence and biology of the daggernose shark Isogomphodon oxyrhynchus (Chondrichthyes: Carcharhinidae) off the Maranhão coast (Brazil). Bulletin of Marine Science, 64(1),115-128.

LESSA, R., SANTANA, F. M., BATISTA, V., \& ALMEIDA, Z. 2000. Age and growth of the daggernose shark Isogomphodon oxyrhynchus from northern Brazil. Marine and Freshwater Research, 51:339-347.

LESSA, R., ALMEIDA, Z., SANTANA, F.M, SIU, S. \& PÉREZ, M. Carcharhinus porosus. The IUCN Red List of Threatened Species 2006: e.T60220A12324372. http://dx.doi.org/10.2305/ IUCN.UK.2006.RLTS.T60220A 12324372. en. Downloaded on 19 July 2017.

LESSA, R., P. CHARVET-ALMEIDA, P., F. SANTANA, AND Z. ALMEIDA. 2006. Isogomphodon oxyrhynchus. In IUCN 2008. 2008 IUCN Red List of Threatened Species. Available: www.iucnredlist.org (January 2018).

LESSA, R., V. BATISTA, AND F. SANTANA. 2016. Close to extinction? The collapse of the endemic Daggernose Shark (Isogomphodon oxyrhynchus) off Brazil. Global Ecology and Conservation 7:70-81.

MABRAGAÑA, E.; GILBERTO, D.A.; BREMEC,
C.S. 2005. Feeding ecology of Bathyraja macloviana (Rajiformes: Arhynchobatidae): a polychaete-feeding skate from the Southwest Atlantic. Scient Mar. 69(3): 405-413.

MARTINS, A.P.B. 2015. Análise da cadeia produtiva e o estado de conservação dos tubarões (Chondrichthyes: Elasmobranchii) no estado do Maranhão com base no conhecimento tradicional dos pescadores. Dissertação de Mestrado. UFMA. São Luis. 75 p.

MEDEIROS, R.M. 1996. Isoietas médias mensais $e$ anuais do Estado do Piauí. Teresina: Secretaria de Agricultura, Abastecimento e Irrigação, Departamento de Hidrometeorologia, 24p.

MENNI, R. C., \& STEHMANN, M. F. W. 2000. Distribution, environment and biology of batoid fishes off Argentina, Uruguay and Brazil, a review. Revista del Museo Argentino de Ciencias Naturales (Nueva Serie) 2(1), 69-109.

McEACHRAN, J. D. \& CARVALHO, M. R. de. 2002. Gymnuridae - Butterfly Rays. In: CARPENTER, K. $E$. (Ed.). The living marine resources of the Western Central Atlantic. Volume 1: Introduction, molluscs, crustaceans, hagfishes, sharks, batoid fishes, and chimaeras. Rome: FAO, p. 575-577

MMA- Ministério do Meio Ambiente. PORTARIA No - 445, DE 17 DE DEZEMBRO DE 2014. Lista Nacional Oficial de Espécies da Fauna Ameaçadas de Extinção - Peixes e Invertebrados Aquáticos. Diário Oficial da União, p127-130. No 245, quintafeira, 18 de dezembro de 2014.

MORGAN, M., CARLSON, J., KYNE, P.M. \& LESSA, R. Carcharhinus acronotus. The IUCN Red List of Threatened Species 2009: e.T161378A5410167. http://dx.doi.org/10.2305/ IUCN.UK.20092.RLTS.T161378A5410167. en. Downloaded on 22 August 2017.

MOTTA, F.S, MOURA, R. L, FRANCINI-FILHO, R. B. \& NAMORA, R. C. 2009. Notas sobre a biologia reprodutiva e alimentar de elasmobrânquios no Parque Estadual Marinho Parcel Manoel Luís, Maranhão - Brasil. Pan-Am.J. Aquat Sci, 4(4): 593-598.

NUNES, J.L.S; ALMEIDA, Z. S.; PIORSKI, N. M. 2005. Raias capturadas pela pesca artesanal em águas rasas do Maranhão- Brasil. Arq. Ciên. Mar. Fortaleza, 38: 49 - 54.

PALMA, J.J.C. 1979. Geomorfologia da Plataforma Continental Norte Brasileira. In: Projeto REMAC. Geomorfologia da Margem Continental Brasileira 
e das Áreas Oceânicas Adjacentes. Rio de Janeiro, PETROBRÁS/CENPES/DINTEP. p. 25-51 (Série Projeto REMAC, 7).

PALMEIRA C.A.M., S.L.F. RODRIGUES-FILHO, J.B.L. SALES, M. VALLINOTO, H. SCHNEIDER \& I. SAMPAIO. 2013. Commercialization of a critically endangered species (largetooth sawfish, Pristis perotteti) in fish markets of northern Brazil: authenticity by DNA analysis. Food Control 34(1): 249-252.

PONTES, P.H.P. \& EL-ROBRINI, M. 2008. Massa d'água da plataforma continental do Maranhão, durante o período seco (novembro, 1997). Boletim do Laboratório de Hidrobiologia, 21:17-24.

PRIMACK, R. B. \& RODRIGUES, E. 2001. Biologia da conservação. Londrina, PR. E. Rodrigues ed., 328 p.

RANGEL, B. S.; RODRIGUES, A.; MOREIRA, R. G. 2018. Use of a nursery area by cownose rays (Rhinopteridae) in southeastern Brazil. Neotrop. ichthyol., Maringá, v. 16, n. 1, e170089.

REILY, B. D., CRAMP, R. L., WILSON, J. M., CAMPBELL, H. A. \& FRANKLIN, C. E. 2011. Branchial osmoregulation in the euryhaline bull shark, Carcharhinus leucas: a molecular analysis of ion transporters. J. Exp. Biol., v. 214, n. 17, p. 2883-2895.

RICHARDS, V. P., HENNING, M., WITZELL, W., SHIVJI, M.S. 2009. Species Delineation and Evolutionary History of the Globally Distributed Spotted Eagle Ray (Aetobatus narinari). J. Hered., Volume 100, Issue 3, May-June 2009, Pages 273-283.

RICHARDSON, P.L., ARNAULT, S., GARZOLI, S., BROWN, W.S. 1994. North Brazil Current Retroflection Eddies. J. Geophys. Res. 99: 997-1014.

RODRIGUES-FILHO, L.F. DA S.; ROCHA, T.C.; RÊGO, P.S.; SCHNEIDER, H.; SAMPAIO, H. \& VALLINOTO, M. 2009. Identification and phylogenetic inferences on stocks of sharks affected by the fishing industry off the Northern coast of Brazil. Genetics and Molecular Biology, 32 (2): 405-413.

RODRIGUEZ, M.S.; CAVALLARO, M.R. \& THOMAS, M.R. 2012. A New Diminutive Species of Loricaria (Siluriformes: Loricariidae) from the Rio Paraguay System, Mato Grosso do Sul, Brazil. Copeia, 2012 (1): 49-56.

LESSA, R., P. CHARVET-ALMEIDA, P., F. SANTANA, AND Z. ALMEIDA. 2006.
Isogomphodon oxyrhynchus. In IUCN 2008. 2008 IUCN Red List of Threatened Species. Available: www.iucnredlist.org (January 2018).

LESSA, R., V. BATISTA, AND F. SANTANA. 2016. Close to extinction? The collapse of the endemic Daggernose Shark (Isogomphodon oxyrhynchus) off Brazil. Global Ecology and Conservation 7:70-81.

MARTINS, A. P. B, E. SILVA-FILHO, L. M. FEITOSA, L. P. N SILVA, Z. S. ALMEIDA, AND J. L. S. NUNES. 2015. Sexual dimorphism of sharks from the Amazonian Equatorial Coast. Universitas Scientiarum 20(3):297-304.

MARTINS, A. P. B., L. M. FEITOSA, R. P. LESSA, Z. S. ALMEIDA, M. HEUPEL, W. M. SILVA, L. TCHAICKA, J. L. S. Nunes. 2018. Analysis of the supply chain and conservation status of sharks (Elasmobranchii: Superorder Selachimorpha) based on fisher knowledge. Plos One 13(3):e0193969.

PALMEIRA, C. A. M., S. L. F. RODRIGUESFILHO, J. B. L. SALES, M. VALLINOTO, H. SCHNEIDER, AND I. SAMPAIO. 2013. Commercialization of a critically endangered species (largetooth sawfish, Pristis perotteti) in fish markets of northern Brazil: authenticity by DNA analysis. Food Control 34(1):249-252.

PRATT-JR., H. AND J. I. CASTRO. 1990. Shark reproduction: Parental investment and limited fisheries, an overview. Page 122 in Gruber, S. Discovering Sharks. Highland: American Littoral Society. Highlands, New Jersey.

RODRIGUES-FILHO, L. F., D. PINHAL, D. SODRÉ, AND M. VALLINOTO. 2012. Shark DNA Forensics:Applications and Impacts on Genetic Diversity. Analysis of Genetic Variation in Animals 269-286.

ROSA, R.S., CASTRO, A.L.F., FURTADO, M., MONZINI, J. \& GRUBBS, R.D. 2006. Ginglymostoma cirratum. The IUCN Red List of Threatened Species 2006: e.T60223A12325895. http:// dx.doi.org/10.2305/IUCN.UK.2006.RLTS. T60223A12325895.en. Downloaded on 20 July 2017.

ROSA R.S. \& O.B.F. GADIG. 2014. Conhecimento da diversidade dos Chondrichthyes marinhos no Brasil: A contribuição de José Lima de Figueiredo. Arquivos de Zoologia. Museu de Zoologia da Universidade de São Paulo. Volume 45(esp.): 89-104. DOI: 10.11606/issn.2176-7793.v45iespp89-104

ROSA, R. \& FURTADO, M. 2016a. Hypanus guttatus. The IUCN Red List of Threatened Species 2016: e.T44592A104125099. http:// 
dx.doi.org/10.2305/IUCN.UK.2016-3.RLTS. T44592A104125099.en. Downloaded on 20 July 2017.

ROSA, R. \& FURTADO, M. 2016b. Hypanus marianae. The IUCN Red List of Threatened Species 2016: e.T45925A104128768. http:// dx.doi.org/10.2305/IUCN.UK.2016-3.RLTS. T45925A104128768.en. Downloaded on 20 July 2017.

SADOWSKY, V. 1971. Notes on the bull shark Carcharhinus leucas in the lagoon region of Cananéia, Brazil. Bol. Inst. Oceanogr., v. 20, n. 2, p. 71-78,

SANTANA, F. M., LESSA, R. 2002. Análise demográfica do cação-quati, Isogomphodon oxyrhynchus na região norte do Brasil (pp. 90-91). Reunião da Sociedade Brasileira para o Estudo de Elasmobrânquios, 3.

SHEPARD, R.N. 1962. The analysis of proximities: multidimensional scaling with an unknown distance function. Psy., 27: 125-140.

SHEPHERD, T. D. \& MYERS, R. A. 2005. Direct and indirect fishery effects on small coastal elasmobranchs in the northern Gulf of Mexico. Ecol. Lett., 8, p.1095-1104.

SILVA, C. M. L.; ALMEIDA, Z. S. 2018. Alimentação de Rhizoprionodon porosus (Elasmobranchii: Carcharhinidae) da costa do Maranhão, Brasil. B. Inst. Pesca, 27 (2), 201-207

SIMPFENDORFER, C. A., HUETER, R. E., BERGMAN, U. AND CONNETT, S. M. H. 2002. Results of a fishery-independent survey for pelagic sharks in the western North Atlantic, 1977-1994. Fisheries Research, 55, 175-192.

SIMPFENDORFER, C. Galeocerdo cuvier. The IUCN Red List of Threatened Species 2009: e.T39378A10220026. http://dx.doi.org/10.2305/ IUCN.UK.20092.RLTS.T39378A 10220026. en. Downloaded on 22 August 2017.

SIMPFENDORFER，C.\& BURGESS, G.H. Carcharhinus leucas. The IUCN Red List of Threatened Species 2009: e.T39372A10187195. http://dx.doi.org/10.2305/ IUCN.UK.2009-2.RLTS.T39372A 10187195. en. Downloaded on 22 August 2017.

SIMPFENDORFER, C \& DULVY, N. 2017. Bright spots of sustainable shark fishing. Curr. Bio.y 27, R83-R102, February 6.
SODRÉ, D., RODRIGUES-FILHO, L. F. S, SOUZA, R. F. C, RÊGO, P. S., SCHNEIDER, H., SAMPAIO, I., \& VALLINOTO, M. 2012. Inclusion of South American samples reveals new population structuring of the blacktip shark (Carcharhinus limbatus) in the western Atlantic. Genet. Mol. Biol., 35 (4), 752-760.

SCHLUESSEL, V. 2008. Life history, population genetics and sensory biology of the white spotted eagle ray Aetobatus narinari (Euphrasen, 1790) with emphasis on the relative importance of olfaction. Ph.D. Thesis, The University of Queensland, Brisbane.

STEVENS, J. D., BONFIL, R., DULVY, N. K. AND WALKER, P. 2000. The effects of fishing on sharks, rays and chimaeras (Chondrichthyans), and the implications for marine ecosystems.ICES Journal of Marine Science, 57, 476-494.

STRIDE, R.K. 1992. Diagnóstico da pesca artesanal marinha do Estado do Maranhão. CORSUP/ EDUFMA, $2^{\circ}$ edição, 205 p., São Luis.

TAVARES, M. C. S., I. FURTADO JUNIOR, R. A. L. SOUZA \& C. S. F. BRITO. 2005. A pesca de curral no estado do Pará. Boletim Técnico-Científico do CEPNOR, 5: 115-139.

VASKE, J. R., T., VOOREN, C. M. \& LESSA, R. P. 2009. Feeding strategy of the Night Shark (Carcharhinus signatus) and Scalloped Hammerhead Shark (Sphyrna lewini) near seamounts off northeastern Brazil. Braz. J. Oceanogr. 57, 97-104.

VISINTIN, M.R. 2012. Avaliação do impacto da pesca de emalhe de fundo no talude do sudeste e sul do Brasil, através de uma análise de produtividade e susceptibilidade (APS). Monografia de Bacharelado em Oceanografia. Universidade do Vale do Itajaí, Itajaí, Santa Catarina, 62 p.

VOOREN, C.M. \& KLIPPEL, S. 2005. Ações para a conservação de tubarões e raias no sul do Brasil. Porto Alegre: Igaré. 262p.

VOOREN, C. M., \& KLIPPEL, S., GALINA, A. B. 2005. Os elasmobrânquios das águas costeiras da Plataforma Sul (pp. 113-120). In: Vooren, C. M., Klippel, S. (Ed.). Ações para a conservação de tubarões e raias no sul do Brasil. Porto Alegre: Igaré.

WALKER, P.A. \& HISLOP, R.G. 1998. Sensitive skates or resilient rays? Spatial and temporal shifts in ray species composition in the central and northwestern North Sea between 1930 and the present day. ICES Journal of Marine Science, v. 55, p. 392-402. 